\title{
An Analytic Solution of Stress Distribution Around a Shallow Buried Hollow Cylinder Karst Cave in Limestone Strata
}

\section{Peng Xie ( $\sim$ Peng_Xie@hainanu.edu.cn )}

Hainan University $\llbracket$ Haikou

\section{Shaokun Ma}

Guangxi University

Haijia Wen

Chongqing University

Shaolong Jie

Shijiazhuang Tiedao University

Junfeng Liu

Dongguan University of Technology

Jie Cui

Hainan University『Haikou

\section{Research Article}

Keywords: Cylinder karst cave, Shallow buried, Spatial stress distribution of surrounding rock, Love displacement function, Three-dimensional explicit finite difference

Posted Date: March 16th, 2021

DOl: https://doi.org/10.21203/rs.3.rs-289765/v1

License: (9) This work is licensed under a Creative Commons Attribution 4.0 International License. Read Full License 


\title{
An analytic solution of stress distribution around a shallow buried hollow cylinder karst cave in limestone strata
}

\author{
Peng Xie ${ }^{1,2}$ a), Shaokun Ma ${ }^{2 \text { b) }}$, Haijia Wen ${ }^{3,4}$,Shaolong Jie ${ }^{5}$, Junfeng Liu ${ }^{6}$, Jie Cui ${ }^{1}$ \\ ${ }^{1}$ College of Civil Engineering and Architecture, Hainan University, Haikou, Hainan 570228, China \\ ${ }^{2}$ Guangxi Key Laboratory of Disaster Prevention and Engineering Safety, Guangxi University, Nanning, \\ Guangxi 530004, China \\ ${ }^{3}$ Key Laboratory of New Technology for Construction of Cities in Mountain Area (Chongqing \\ University), Ministry of Education, Chongqing 400045, China \\ ${ }^{4}$ School of Civil Engineering, Chongqing University, Chongqing 400045, China \\ ${ }^{5}$ School of Civil Engineering, Shijiazhuang Tiedao University, Shijiazhuang, Hebei 050043, China \\ ${ }^{6}$ School of Environment and Civil Engineering, Dongguan University of Technology, Dongguan, \\ Guangdong, 523808, China \\ Corresponding E-mail: \\ a) Peng Xie@hainanu.edu.cn \\ b) 261688417@qq.com
}

\begin{abstract}
The chief objective of the article is to learn the spatial characteristics of stress distribution around a shallow buried cylinder karst cave in limestone strata. Firstly, taking into account the geometry of limestone formations, and the characteristics of karst geomorphology in China, a spatial axial-symmetrical hollow model was established. Concurrently, combing available work and the concept of elasticity, the boundary conditions are determined. Subsquently, Love displacement method was introduced, in addition to the expressions of stress components were gained. The diagram characteristics of each stress component are summarized, which are affected by various influencing factors. Finally, in order to prove the rationality of the general solution, a numerical simulation was carried out on the basis of practical engineering, and the maximum error is less than $5 \%$. Thus, the analytical solution could represent the spatial characteristics of stress distribution around a shallow buried cylinder karst cave in limestone strata.
\end{abstract}

Keywords: Cylinder karst cave; Shallow buried; Spatial stress distribution of surrounding rock; Love displacement function; Three-dimensional explicit finite difference

\section{INTRODUCTION}

Karst geomorphology exists widely in the world, and karst cave is one of the typical representatives. Up to now, various patterns of Karst cave has been found, including columnar, alter shaped, spherical, funnel shaped and so on ${ }^{1,2}$. China is one of the countries, where karstification is widely developed. It is found that carbonate rocks cover a part of approximately 3.25 million $\mathrm{km}^{2}$ in China, different from abroad3. Within this area, buried rock accounts for about $2 / 3^{3}$. In recent years, owing to the quick urban development as well as growing occupation of terrestrial, the extents as well as the speed of engineering construction have been greatly accelerated ${ }^{4}$. Ground collapse is a common engineering 
problem in mantled Karst region, and brings great loss to people's life and property. According to incomplete statistics, the annual economic loss caused by karst ground collapse in 24 provinces (cities and districts) in China amounts to more than 120 million yuan. The losses are related to agricultural engineering, highway engineering, railway engineering, mining engineering, industrial and civil construction engineering, etc ${ }^{5-8}$. Therefore, the prevention and control of ground collapse is an important requirement for national security and economic development.

Commonly, carbonate rocks are softened by faintly acidic waters ${ }^{9-11}$. Then, a series of buried karst caves formed near subsurface. Karst caves may provide transport channel or storage space for overlying rock and soil mass, and cause the change of spatial stress distribution. Furthermore, affected by natural and human factors, ground collapse may happen. In order to investigate the effect on spatial stress distribution ,caused by buried Karst caves, a lot of research work was performed. Goodier ${ }^{12}$ presented that there is a concentration around void or defect. In order to achieve quantitative expression of stress distribution, Howland et al. ${ }^{13}$ simplified the problem into a thin plate containing circular holes, and inverse method was used to solved the problem. Taking into account the variety of Karst caves and the complexity of loading conditions, Rao et al. ${ }^{14}$ analysed the stresses of surrounding rock containing a tubular filled elliptical karst cave, and the analytic general formula for the component of stresse were solved. Li et al. ${ }^{15}$ established the plane mechanical models with different stress boundary conditions in each direction, and the exact general solution was obtained. Shi et al. ${ }^{\mathbf{1 6}}$ summarized the stress distribution around rectangular cavity. Considering the spatial geometric characteristics of Karst caves, Liao et al. ${ }^{17}$ provided the extreme value of critical point on the wall of an elliptical spherical cavity under triaxial stress.

To sum up, A large number of studies on the stress distribution characteristics of surrounding rock containing shallow buried Karst caves has been made. However, complex function theory was mainly used, and the method is relatively single. In addition, spatial geometry of strata is neglected. Therefore, this paper is to study the spatial stress distribution characteristics around a shallow buried cylinder karst cave in limestone strata. Firstly, taking into account the geometry of limestone formations, a spatial axial-symmetrical model was established. Concurrently, on the basis of the theory of elasticity, the expressions of stress components were obtained. Finally, a numerical simulation was carried out to prove the rationality of the general solution.

\section{MECHANICAL MODEL}

According to the characteristic of karst geomorphology in China, karst caves are usually shallow buried, and affected by external load and stress field in the Earths crust (Fig. 1). The mechanical model can be simplified into a spatial axial-symmetrical model in this study $(h<2.5 D$, the hidden depth of the karst cave is $h$, the span of the karst cave is $D$ ), and the cylindrical coordinates $(r, \theta, z)$ is chosen as the coordinate system (Fig. 2). The parameters are $\gamma$ (unit weight), $\mu$ (poisson's ratio) and $E$ (elastic modulus) respectively. The effect generated by external loads and the gravity of overlying limestone are simplified into vertical uniform distributed loads. In addition, stress field in the Earths crust will cause vertical stress on the bottom and horizontal stress surrounding the karst cave (the side force coefficient $k_{0}=\mu /(1-\mu)$ ). 


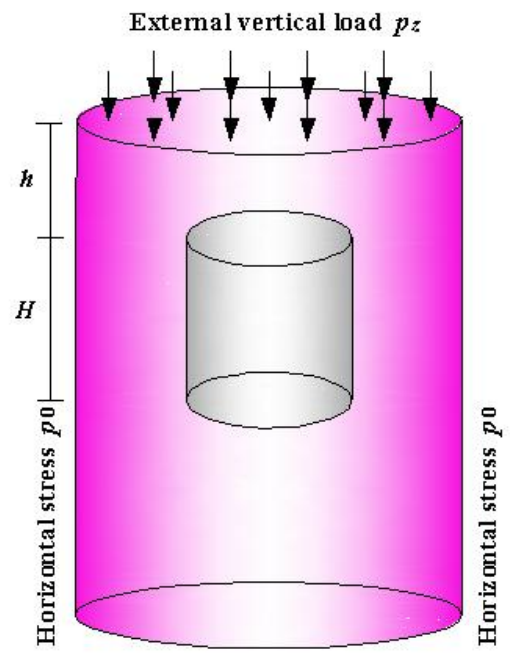

FIG. 1. Sketch of limestone strata in a mantled Karst region, containing shallow buried cylinder Karst cave

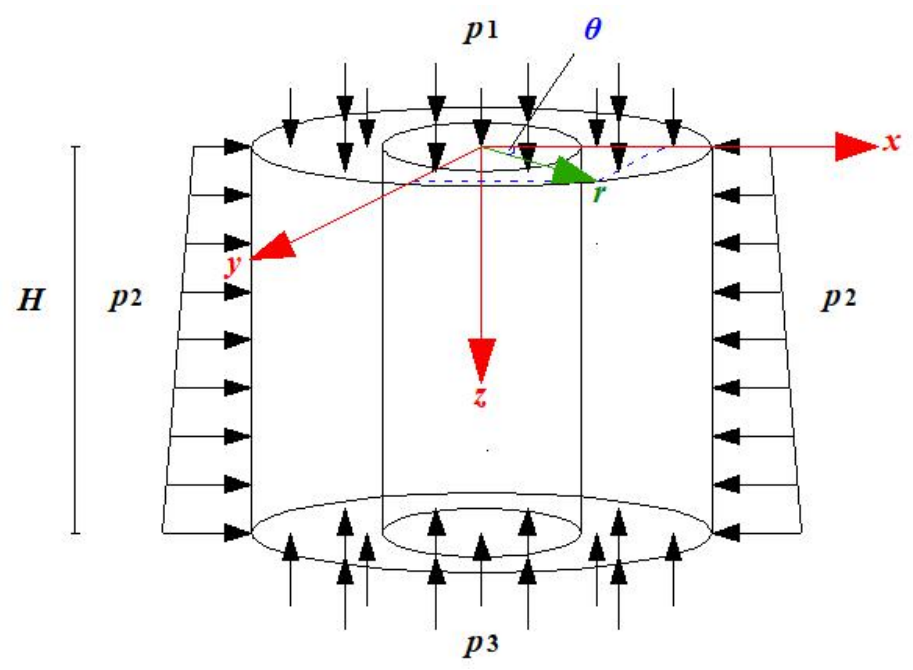

FIG. 2. Mechanical model

The parameters in Fig. 1 and Fig. 2 are

$p_{1}$ — the overburden load, $p_{1}=p_{z}+\gamma h$;

$p_{2}-$ horizontal stress stress caused by field in the Earths crust, $p_{2}=k_{0}\left[p_{1}+\chi(h+z)\right]$;

$p_{1}$ — vertical stress on the bottom of the buried cylinder karst cave, $p_{3}=p_{z}+\chi(h+H)$;

$\gamma$ the unit weight of limestone strata;

$h$ - the depth of the overburden limestone strata;

$r$ - the radius of the buried cylinder karst cave;

$R_{1}$ — the radius of the buried cylinder karst cave;

$H$ — the depth of the buried cylinder karst cave;

$k_{0}$ — the side force coefficient , $k_{0}=\mu /(1-\mu)$. 
Combining available work and the concept of elasticity, the boundary conditions are as follows:

(1) $z=0, \sigma_{z}=p_{z}+\gamma h$;

(2) $z=H, \quad \sigma_{z}=p_{z}+\gamma(h+H)$;

(3) $r \rightarrow \infty, \sigma_{r}=\left[\left(p_{z}+\gamma(h+z)\right] \mu /(1-\mu)\right.$;

(4) $r=R_{1}, \sigma_{r}=0$;

(5) $r=R_{1}, \tau_{r z}=0$;

\section{THEORETICAL ANALYSIS}

\section{A. The basic theory ${ }^{18}$}

Taking into account the influence of gravity, the equilibrium differential equations are expressed as

$$
\left.\begin{array}{c}
\frac{\partial \sigma_{r}}{\partial r}+\frac{\partial \tau_{z r}}{\partial z}+\frac{\sigma_{r}-\sigma_{\theta}}{r}=0 \\
\frac{\partial \sigma_{z}}{\partial z}+\frac{\partial \tau_{z r}}{\partial r}+\frac{\tau_{z r}}{r}+\gamma=0
\end{array}\right\}
$$

Love displacement method is an effective way, the stress components are as follows

$$
\left.\begin{array}{l}
\sigma_{r}=\frac{\partial}{\partial z}\left(\mu \nabla^{2}-\frac{\partial^{2}}{\partial r^{2}}\right) \phi(r, z) \\
\sigma_{\theta}=\frac{\partial}{\partial z}\left(\mu \nabla^{2}-\frac{1}{r} \frac{\partial}{\partial r}\right) \phi(r, z) \\
\sigma_{z}=\frac{\partial}{\partial z}\left[(2-\mu) \nabla^{2}-\frac{\partial^{2}}{\partial z^{2}}\right] \phi(r, z) \\
\tau_{r z}=\frac{\partial}{\partial r}\left[(1-\mu) \nabla^{2}-\frac{\partial^{2}}{\partial z^{2}}\right] \phi(r, z)
\end{array}\right\}
$$

Where $\nabla^{2}$ is Laplace operator

\section{B. The general solution}

In this study, cylindrical coordinate system was selected as the coordinate system. Love displacement function (Equation (2)) was established, which meets Equation (1) ${ }^{\mathbf{1 8 - 2 0}}$.

$$
\varphi=A_{1} z^{4}+A_{2} r^{4}+A_{3} z^{3}+A_{4} z^{2} r^{2}+A_{5} z r^{2}+A_{6} z^{2} \ln r+A_{7} z \ln r+A_{8} r^{2} \ln r
$$

where, $A_{i}(i=1 \ldots 8)$ are the undetermined coefficients

Substituting Equation (3) into Equation (2) yields

$$
\sigma_{r}=4\left[6 \mu A_{1}+(2 \mu-1) A_{4}\right] z+2\left[3 \mu A_{3}+(2 \mu-1) A_{5}\right]+2 A_{6} \frac{z}{r^{2}}+A_{7} \frac{1}{r^{2}}
$$




$$
\begin{gathered}
\sigma_{\theta}=4\left[6 \mu A_{1}+(2 \mu-1) A_{4}\right] z+2\left[3 \mu A_{3}+(2 \mu-1) A_{5}\right]-2 A_{6} \frac{z}{r^{2}}-A_{7} \frac{1}{r^{2}} \\
\sigma_{z}=8\left[3(1-\mu) A_{1}+(2-\mu) A_{4}\right] z+2\left[3(1-\mu) A_{3}+2(2-\mu) A_{5}\right] \\
\tau_{r z}=4\left[8(1-\mu) A_{2}-\mu A_{4}\right] r-2 \mu A_{6} \frac{1}{r}+4 A_{8} \frac{(1-\mu)}{r}
\end{gathered}
$$

Equation (4)-(7) are proved to satisfy Equation (1), so

$$
3 A_{1}+8 A_{2}+2 A_{4}=\frac{\gamma}{8(\mu-1)}
$$

Substituting boundary condition (1) into Equation (6)

$$
6(1-\mu) A_{3}+4(2-\mu) A_{5}=p_{z}+\gamma h
$$

Substituting boundary condition (2) into Equation (6) yields

$$
8\left[3(1-\mu) A_{1}+(2-\mu) A_{4}\right] H+2\left[3(1-\mu) A_{3}+2(2-\mu) A_{5}\right]=p_{z}+\gamma(h+H)
$$

Substituting boundary condition (3) into Equation (4), as follows.

$$
4\left[6 \mu A_{1}+(2 \mu-1) A_{4}\right] z+2\left[3 \mu A_{3}+(2 \mu-1) A_{5}\right]=\frac{\mu}{1-\mu}\left[\left(p_{z}+\gamma h\right)+\gamma z\right]
$$

Matching the equivalent coefficients of both sides of Equation (11) leads to

$$
\begin{gathered}
24 \mu A_{1}+4(2 \mu-1) A_{4}=\frac{\mu}{1-\mu} \gamma \\
6 \mu A_{3}+2(2 \mu-1) A_{5}=\frac{\mu}{1-\mu}\left(p_{z}+\gamma h\right)
\end{gathered}
$$

Substituting boundary conditions (4) and (5) into Equation (4) and (7) respectively

$$
\begin{gathered}
24 \mu A_{1}+4(2 \mu-1) A_{4}+2 A_{6} \frac{1}{R_{1}^{2}}=0 \\
6 \mu A_{3}+2(2 \mu-1) A_{5}+A_{7} \frac{1}{R_{1}^{2}}=0 \\
32(1-\mu) A_{2} R_{1}-4 \mu A_{4} R_{1}-2 \mu A_{6} \frac{1}{R_{1}}+4 A_{8} \frac{(1-\mu)}{R_{1}}=0
\end{gathered}
$$

Combining Equation (8)-(10) and Equation (12)-(16), the undetermined coefficients are solved $A_{1}=\frac{\gamma}{24(1-\mu)}, \quad A_{2}=\frac{\gamma}{32(\mu-1)}, \quad A_{3}=\frac{p_{z}+\gamma h}{6(1-\mu)}, \quad A_{4}=A_{5}=0, \quad A_{6}=\frac{\mu R_{1}^{2}}{2(\mu-1)} \gamma$, 


$$
A_{7}=\frac{\mu R_{1}^{2}}{\mu-1}\left(p_{z}+\gamma h\right), \quad A_{8}=\frac{\left(1-\mu-\mu^{2}\right) \gamma R_{1}^{2}}{4(1-\mu)^{2}}
$$

Substituting the expressions of the undetermined coefficients into Equation (4)-(7) yields

$$
\begin{gathered}
\sigma_{r}=\frac{\mu \gamma}{1-\mu} z+\frac{\mu}{1-\mu}\left(p_{z}+\gamma h\right)-\frac{\mu \gamma R_{1}^{2}}{1-\mu} \frac{z}{r^{2}}-\frac{\mu R_{1}^{2}\left(p_{z}+\gamma h\right)}{1-\mu} \frac{1}{r^{2}} \\
\sigma_{\theta}=\frac{\mu \gamma}{1-\mu} z+\frac{\mu}{1-\mu}\left(p_{z}+\gamma h\right)+\frac{\mu \gamma R_{1}^{2}}{1-\mu} \frac{z}{r^{2}}+\frac{\mu R_{1}^{2}\left(p_{z}+\gamma h\right)}{1-\mu} \frac{1}{r^{2}} \\
\sigma_{z}=\gamma z+\left(p_{z}+\gamma h\right) \\
\tau_{r z}=\gamma\left(R_{1}{ }^{2} \frac{1}{r}-r\right)
\end{gathered}
$$

\section{DISTRIBUTION CHARACTERISTICS AND VALIDATION OF THE PROPOSED ANALYTICAL SOLUTION}

\section{A. Distribution characteristics of stress component}

In order to display the distribution characteristics of each stress component, the data are substituted into the expressions of each stress component, and the diagram of each stress component are drawn using MATLAB software.

For radial pressure and tangential pressure, there are two influencing factors, one is the radius $(r)$, another is the depth $(z)$. The figures of circumferential stress and radial stress are comparable to a paraboloid (Fig. 3). Nevertheless, the tendency of value alteration is the opposed.

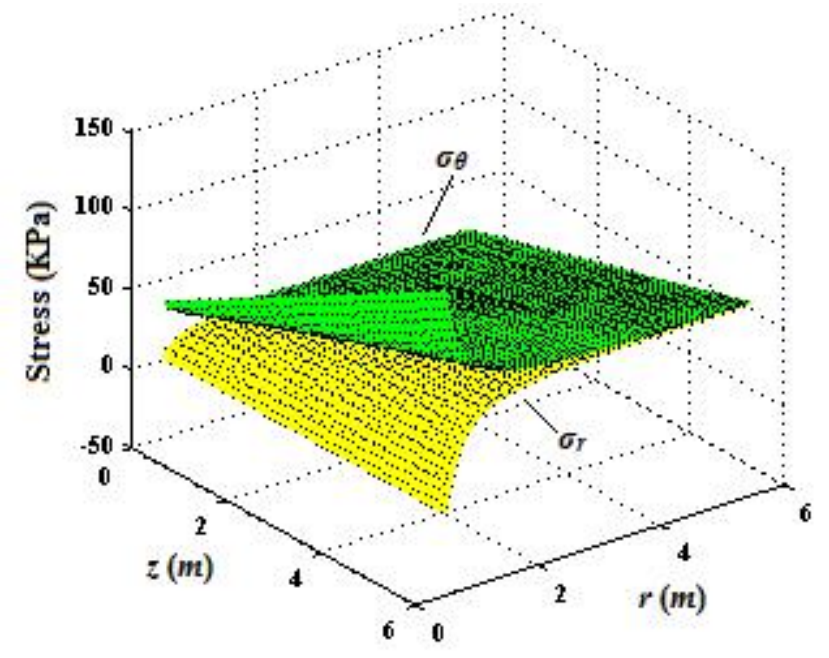

FIG. 3. The distribution of radial stress and circumferential stress .

Furthermore, to discuss the effect of the depth $(z)$ as well as the radius $(r)$, the variation curves under the influence of single factor are drawn when depth $(z=3 m)$ and radius $(r=1 \mathrm{~m})$ are constant respectively (Fig. 4). Fig. 4(a) shows that the circumferential stress and radial stress has a reverse trend with the increase of radius value, but the change ratio is consistent. In the meanwhile, with the 
increase of depth, the values of the circumferential stress and radial stress increase commonly. and for the change ratio, the circumferential stress is more obvious (Fig. 4(b)).

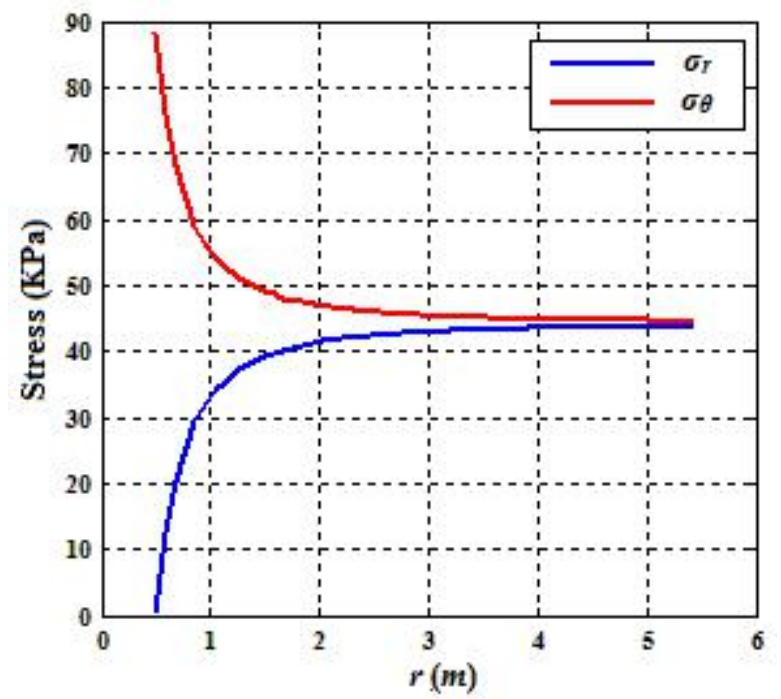

(a)

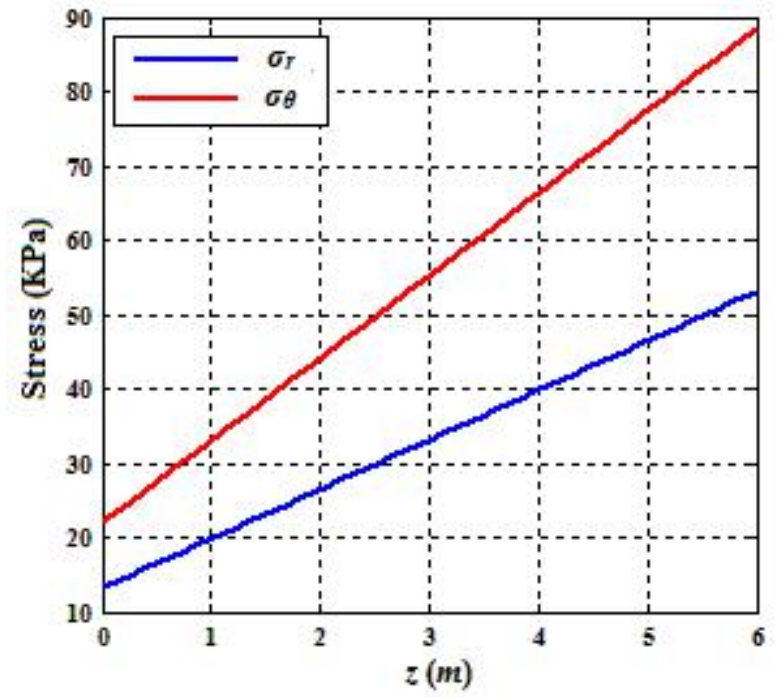

(b)

FIG. 4. The distribution of radial stress and circumferential stress effected by single influencing factor (a) depth is constant $(z=3 \mathrm{~m})$, radius varies from $0.5 \mathrm{~m}$ to $5.5 \mathrm{~m}$ (b) radius is constant ( $r=1 \mathrm{~m})$, the depth varies from $0 \mathrm{~m}$ to $6 \mathrm{~m}$

Fig. 5 and Fig. 6 are the diagrams of vertical stress and shear stress respectively. For vertical stress, depth $(z)$ is the influencing factor, in addition to the curve of vertical stress is linear (Fig. 5). For shear stress, radius $(r)$ is the influencing factor, in addition to the curve of shear stress is nonlinear (Fig. $6)$. 


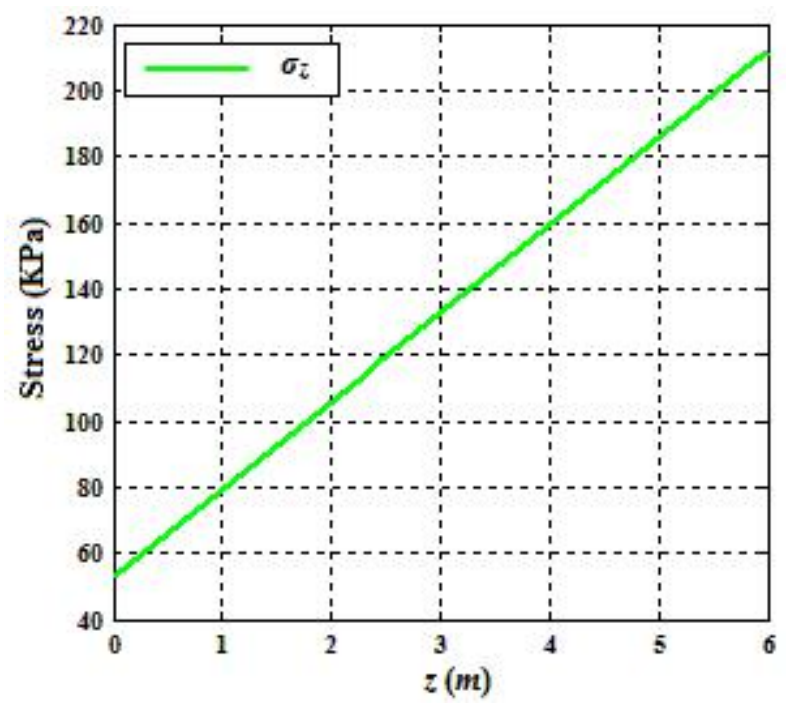

FIG. 5. The distribution of vertical stress

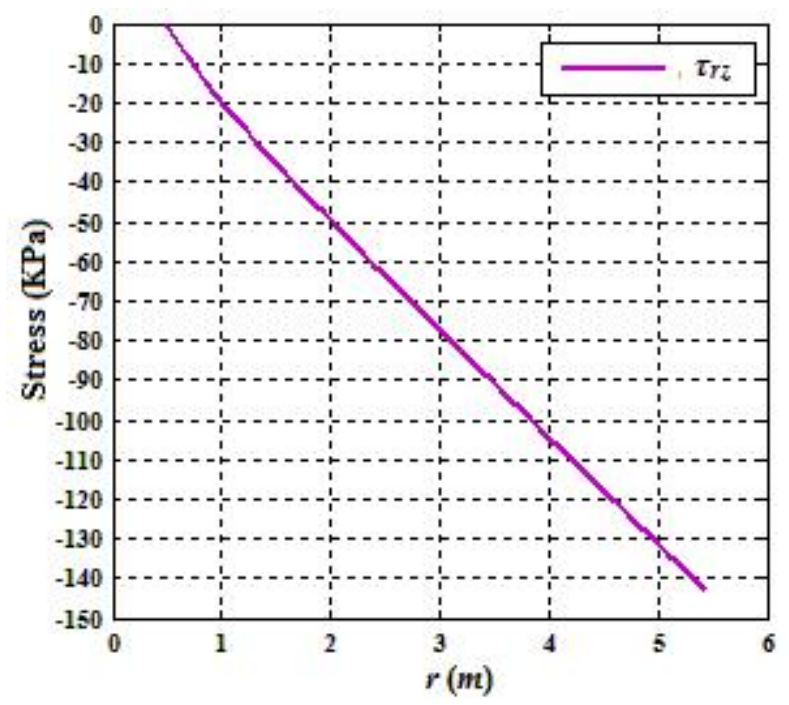

FIG. 6. The distribution of shear stress

\section{B. Validation test of general solution}

So as to confirm the justification of general solution, a mathematical model was conducted, and rectangular coordinate system was employed. According to ground penetrating radar survey and laboratory analysis of rock in Chongqing, The parameters of buried karst cave and thick limestone are shown in Table 1.The dimension and mesh of numerical model are shown in Fig. 7. Through mathematical model, constraints were applied to the bottom of the model in the upright and horizontal direction, and the excavation of void is used to simulate the formation of natural karst cave. Horizontal stress surrounding the karst cave is $p_{2}=8.833 .5 z$ ( $z$ is vertical coordinate value), which is caused by stress field in the Earths crust (Fig. 8). The facts on the line $L_{1}$ were recycled to monitor the horizontal as well as vertical stress (Fig. 9), in addition to the monitoring results are revealed in Table 2-4. 
TABLE 1. Parameters of buried karst cave and thick limestone

\begin{tabular}{lcccccc} 
Natural unit & Elastic \\
meight $\left(\mathrm{kN} / \mathrm{m}^{3}\right)$ & $\begin{array}{c}\text { Poisson's } \\
(\mathrm{GPa})\end{array}$ & ratio & $\begin{array}{c}\text { Radius of } \\
\text { cylinder karst } \\
\text { cave }(\mathrm{m})\end{array}$ & $\begin{array}{c}\text { External load } \\
(\mathrm{KPa})\end{array}$ & $\begin{array}{c}\text { Buried depth of } \\
\text { cylinder karst } \\
\text { cave (m) }\end{array}$ \\
\hline Karst cave / Limestone & 26500 & 35 & 0.25 & 0.5 & 0 & 2
\end{tabular}
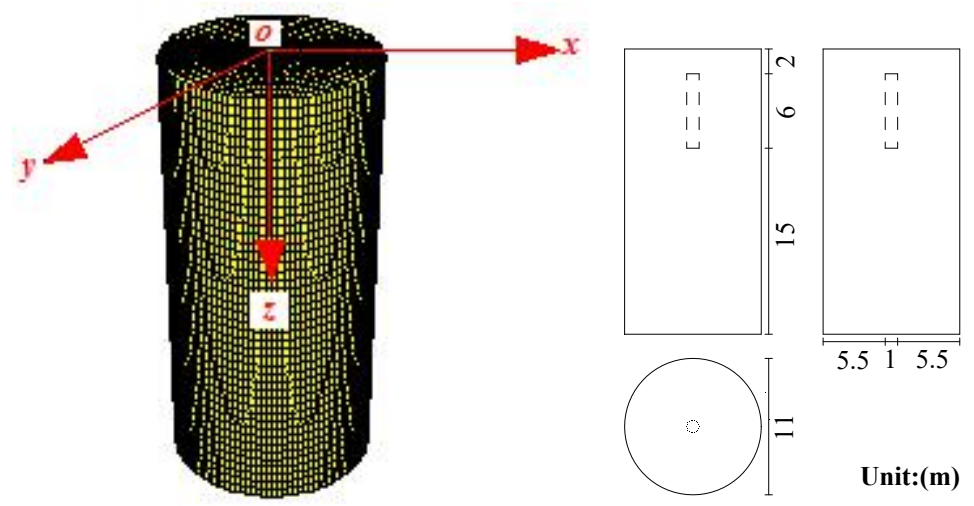

Fig. 7. Sketch of model for numerical simulation

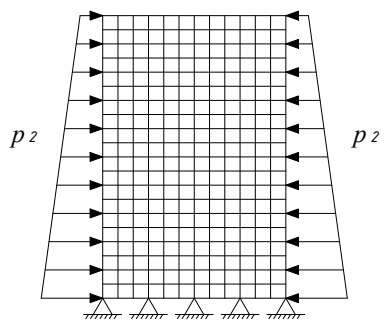

(a) vertical cross-section

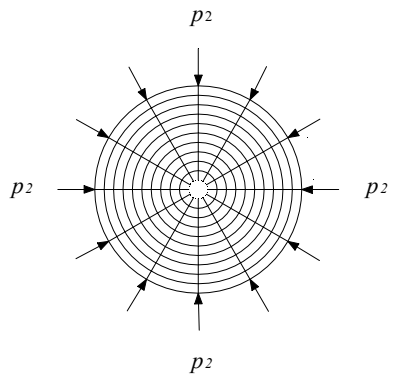

(b) horizontal cross-section

Fig. 8. Sketch of constrained condition and boundary condition for numerical simulation model 


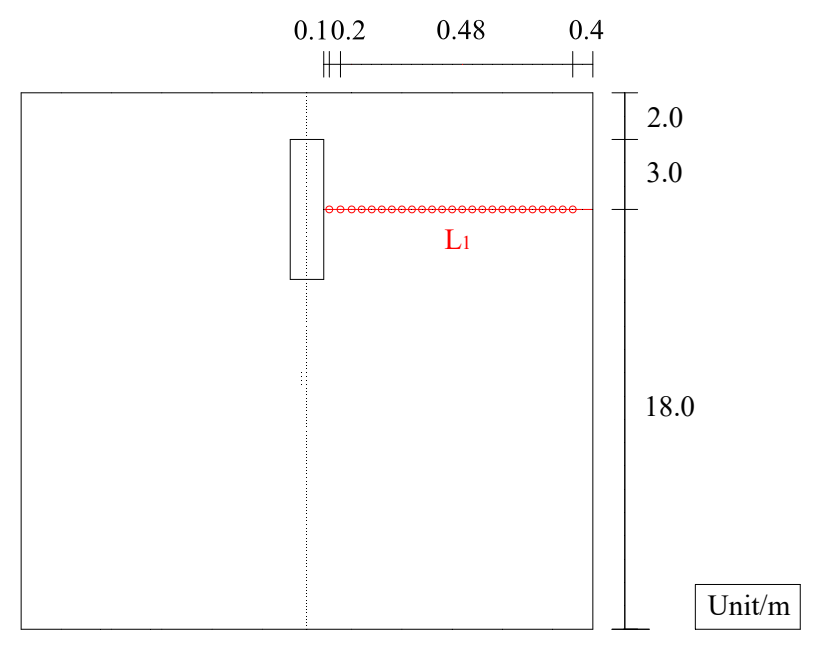

FIG. 9. The layout of monitored area

TABLE 2. The monitoring facts of normal stress $\sigma_{\mathrm{x}}$

\begin{tabular}{|c|c|c|c|c|c|}
\hline$r(m) /[\mathrm{z}=3.0 m]$ & 0.6 & 0.8 & 1.0 & 1.2 & 1.4 \\
\hline$\sigma_{\mathrm{x}}(M P a)$ & 6.00 & 24.25 & 30.56 & 36.21 & 37.21 \\
\hline$r(m) /[\mathrm{z}=3.0 m]$ & 1.6 & 1.8 & 2.0 & 2.2 & 2.4 \\
\hline$\sigma_{\mathrm{x}}(M P a)$ & 40.38 & 40.39 & 41.40 & 41.63 & 41.62 \\
\hline$r(m) /[\mathrm{z}=3.0 m]$ & 2.6 & 2.8 & 3.0 & 3.2 & 3.4 \\
\hline$\sigma_{\mathrm{x}}(M P a)$ & 42.27 & 42.30 & 42.30 & 42.74 & 42.23 \\
\hline$r(m) /[\mathrm{z}=3.0 m]$ & 3.6 & 3.8 & 4.0 & 4.2 & 4.4 \\
\hline$\sigma_{\mathrm{x}}(M P a)$ & 43.05 & 43.06 & 43.06 & 43.32 & 43.32 \\
\hline$r(m) /[\mathrm{z}=3.0 m]$ & 4.6 & 4.8 & 5.0 & 5.2 & 5.4 \\
\hline$\sigma_{\mathrm{x}}(M P a)$ & 43.52 & 43.52 & 43.67 & 43.67 & 43.66 \\
\hline
\end{tabular}

TABLE 3. The monitoring facts of normal stress $\sigma_{\mathrm{y}}$

\begin{tabular}{|c|c|c|c|c|c|}
\hline$r(m) /[\mathrm{z}=3.0 m]$ & 0.6 & 0.8 & 1.0 & 1.2 & 1.4 \\
\hline$\sigma_{\mathrm{y}}(K P a)$ & 80.14 & 68.75 & 54.79 & 51.17 & 51.09 \\
\hline$r(m) /[\mathrm{z}=3.0 m]$ & 1.6 & 1.8 & 2.0 & 2,2 & 2.4 \\
\hline$\sigma_{\mathrm{y}}(K P a)$ & 47.66 & 47.66 & 46.89 & 46.27 & 46.26 \\
\hline$r(m) /[\mathrm{z}=3.0 m]$ & 2.6 & 2.8 & 3.0 & 3.2 & 3.4 \\
\hline$\sigma_{\mathrm{y}}(K P a)$ & 45.57 & 45.57 & 45.57 & 45.2 & 45.2 \\
\hline$r(m) /[\mathrm{z}=3.0 m]$ & 3.6 & 3.8 & 4.0 & 4.2 & 4.4 \\
\hline$\sigma_{\mathrm{y}}(K P a)$ & 44.98 & 44.98 & 44.97 & 44.84 & 44.85 \\
\hline$r(m) /[\mathrm{z}=3.0 m]$ & 4.6 & 4.8 & 5.0 & 5.2 & 5.4 \\
\hline$\sigma_{\mathrm{y}}(K P a)$ & 44.78 & 44.77 & 44.74 & 44.74 & 44.74 \\
\hline
\end{tabular}


TABLE 4. The monitoring facts of normal stress $\sigma_{z}$

\begin{tabular}{|c|c|c|c|c|c|}
\hline$r(m) /[\mathrm{z}=3.0 m]$ & 0.6 & 0.8 & 1.0 & 1.2 & 1.4 \\
\hline$\sigma_{\mathrm{z}}(\mathrm{KPa})$ & 132.48 & 132.47 & 132.51 & 132.49 & 132.50 \\
\hline$r(m) /[\mathrm{z}=3.0 m]$ & 1.6 & 1.8 & 2.0 & 2.2 & 2.4 \\
\hline$\sigma_{\mathrm{z}}(\mathrm{KPa})$ & 132.50 & 132.50 & 132.50 & 132.50 & 132.50 \\
\hline$r(m) /[\mathrm{z}=3.0 m]$ & 2.6 & 2.8 & 3.0 & 3.2 & 3.4 \\
\hline$\sigma_{\mathrm{z}}(K P a)$ & 132.50 & 132.50 & 132.50 & 132.50 & 132.50 \\
\hline$r(m) /[\mathrm{z}=3.0 m]$ & 3.6 & 3.8 & 4.0 & 4.2 & 4.4 \\
\hline$\sigma_{\mathrm{z}}(K P a)$ & 132.50 & 132.50 & 132.50 & 132.50 & 132.50 \\
\hline$r(m) /[\mathrm{z}=3.0 m]$ & 4.6 & 4.8 & 5.0 & 5.2 & 5.4 \\
\hline$\sigma_{\mathrm{z}}(K P a)$ & 132.50 & 132.50 & 132.50 & 132.50 & 132.50 \\
\hline
\end{tabular}

Owing to theoretical analysis and numerical simulation were carried in different coordinate system, the monitoring statistics was converted into the standards in cylindrical coordinates using Equations (21)-(23). Fig. 10 presents the monitoring data and calculation value of stress component together. For vertical stress, the theoretical calculation value is consistent with monitoring facts. For radial stress as well as tangential stress, the extreme fault is not more than $5.0 \%$, which meets the proposal standard necessity in practice.

$$
\begin{gathered}
\sigma_{r}=\sigma_{x} \cos ^{2} \theta+\sigma_{y} \sin ^{2} \theta+2 \tau_{x y} \sin \theta \cos \theta \\
\sigma_{\theta}=\sigma_{x} \sin ^{2} \theta+\sigma_{y} \cos ^{2} \theta-2 \tau_{x y} \sin \theta \cos \theta \\
\sigma_{z}=\sigma_{z}
\end{gathered}
$$

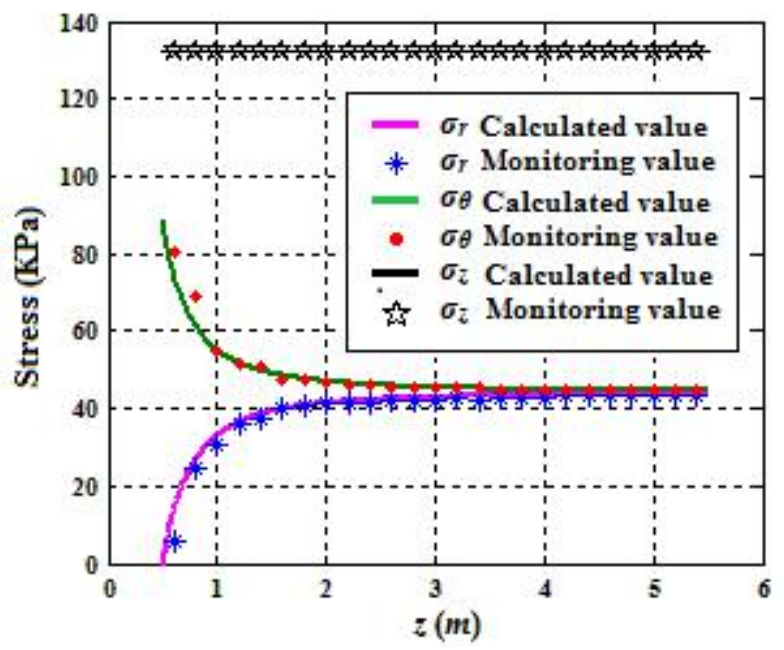

FIG. 10. Comparisons of stress component between analytical solution and numerical simulation. 


\section{DISCUSSION}

In summary, the expressions of stress components are composed of power function, which are beneficial to the application in practice. Nevertheless, there is a fault (the maximum fault is not more than 5.0\%) for radial stress as well as tangential stress, it's necessary to optimize the analytic solution in the future. On the one hand, increase the type of Love displacement function component may be an effective way. On the other hand, various method could be introduced.

\section{CONCLUSION}

Taking into account the geometry of limestone formations, and the characteristics of karst geomorphology in China, a spatial axial-symmetrical hollow model was generated. A general solution of stress components was gained using Love displacement method .

For radial stress and tangential stress, there are two influencing factors, one is the radius $(r)$, another is the depth $(z)$. The diagrams of the radial stress as well as tangential stress are comparable to a paraboloid, in addition to the values tend to a common constant. Nevertheless, the tendency of value variation is the contradictory. When the value of depth $(z)$ is consistent, the radial stress and circumferential stress has a reverse trend with the increase of radius value, but the change ratio is consistent. In the meanwhile, when the value of radius $(r)$ is consistent, the values of the circumferential pressure and radial pressure growth commonly with the increase of depth. For the change ratio, the circumferential stress is more obvious. The depth $(z)$ as well as the radius $(r)$ are influencing factor for vertical stress and shear stress respectively. The curve of the vertical stress is linear, in addition to the diagram of shear stress is nonlinear.

Based on ground penetrating radar survey and laboratory analysis of rock in Chongqing, a mathematical model was conducted, and the judgement in the middle of monitoring data and calculation value of stress component was carried out. For vertical stress, the calculation value using general solution is consistent with the monitoring data. For radial stress as well as tangential stress, the maximum fault is not more than $5.0 \%$, which meets the proposal standard necessity in practice. As a result, the analytical solution could represent the spatial characteristics of stress distribution around a shallow buried cylinder karst cave in limestone strata.

\section{ACKNOWLEDGEMENTS}

The authors are grateful to Yanyan Zhang, Jing Hu and Xiaoxuan Zhang for their assistance.

No potential conflflict of interest was reported by the author.

The research on which this article is based has been supported by grants: the Systematic Project of Guangxi Key Laboratary of Disaster Prevention Structural Safety (Grant No:2019ZKX015), Natural Science Foundation of Hebei Province (No. E2020210006), the Scientific Research Startup Foundation of Hainan university (Grant No:KYQD(2R)1723), Key Research and Development Project of Cangzhou Municipal Science and Technology bureau,China(Grant No.183305006), National Key R\&D Program of China (Grant No. 2018YFC1505501).National Natural Science Foundation of China (42002293).

\section{DATA AVAILABLE STATEMENT}

Data available in article or supplementary material 
${ }^{1}$ F. Gutierrez, M. Parise, J. Dewaele, and H. Jourde, "A review on natural and human-induced geohazards and impacts in karst”. Earth-Science Reviews, 138, 61-88 (2014).

${ }^{2}$ P. Xie, H. J. Wen, P. Xiao, and Y. Y. Zhang, "Evaluation of ground-penetrating radar (GPR) and geology survey for slope stability study in mantled karst region". Environmental Earth Sciences, 77, 122 (2018).

${ }^{3}$ H. J. Zhao, F. S. Ma, and J. Guo, "Regularity and formation mechanism of Large-scale abrupt karst collapse in southern China in the first half of 2010". Nat Hazard, 60, 1037-1045 (2012).

${ }^{4}$ P. Xie, H. J. Wen, Y. Y. Zhang, X. X. Zhang, and J. Hu, "A method for identification and reconstruction of hard structural planes, weak interlayer, and cavities in the limestone near surface”. European Journal of Environmental and Civil Engineering, 24(14), 2489-2511(2020).

${ }^{5}$ A. S. Scotto, and S. A. Forte, "Analysis of sinkhole triggering mechanisms in the hinterland of Naples (southern Italy”. Engineering Geology, 237, 42-52(2018).

${ }^{6}$ G. Kaufmann, D. Romanov, T. Tippelt, T. Vienken, U Werban, P. Dietrich, F. Mai, and F. Börner, "Mapping and modelling of collapse sinkholes in soluble rock: The Münsterdorf site, northern Germany". Journal of Applied Geophysics, 154, 64-80(2018).

${ }^{7}$ D. D. Wan, "The Traders' Cave of Niah (NW Borneo): morphology and features as indicators of speleogenesis and karstification". Carbonates Evaporites, 33, 315-329(2018).

${ }^{8}$ P. Harris, S. Purkis, and B. Reyes, "Statistical pattern analysis of surficial karst in the Pleistocene Miamioolite of South Florida ". Sedimentary Geology, 367, 84-95(2018) .

${ }^{9}$ L. F. Zhang, X. S. Zeng, Y. S. Yao, and W. L. Liao, "Review on karst collapse in China", The Chinese Journal of Geological Hazard and Control, 18(3),126-130(2007). (in Chinese)

${ }^{10} \mathrm{P}$. W. Williams, "The role of the epikarst in karst and cave hydrogeology: a review". Int. J. Speleol, 37, 1-10(2008).

${ }^{11}$ L. Piccini, and M. Mecchia, "Solution weathering rate and origin of karst landforms and caves in the quartzite of Auyan-tepui (Gran Sabana, Venezuela)". Geomorphology, 106, 15-25(2009).

12 J. N. Goodier, "Concentrations of stress around spheroidal and cylindrical inclusions and flaws". Journal of Applied Mechanics, 55, 39-44(1933).

${ }^{13}$ R. C. J. Howland, and R. C. Knight, "Stress functions for a plate containing groups of circular holes". Philosophical Transactions of the Royal Society A: Mathematical and Physical Sciences, 238(2), 357-392(1939).

${ }^{14}$ J. Y. Rao, H. L. Fu, Y. S. Liu, and Q Yin, "Stress analysis of rocks surrounding a tubular filled elliptical karst cave with complex function of elastic mechanics". Journal of Central South University (Science and Technology), 46(7), 2605-2612(2015). (in Chinese)

${ }^{15}$ Q. Q. Li, D. L. Zhang, and Q Fang. "Analytic solution to initial damage of cavern strata by complex function method". Chinese Journal of Geotechnical Engineering, 36(11), 2110-2117(2014). (in Chinese)

${ }^{16}$ G. P. Shi, J. H. Zhu, B. H. Li, and J. H. Yang. "Elastic analysis of hole-edge stress of rectangular roadway". Rock and Soil Mechanics, 35(9), 2587-2593(2014). (in Chinese)

17 L. P. Liao, W. K. Yang, and Q. Z. Wang. "Stability analysis of an ellipsoidal cavity in foundation". 
Rock and Soil Mechanics, 31(S2), 138-147(2010). (in Chinese)

18 S. Timoshenko, J. N. Goodier, Theory of elasticity [M]. Xu Zhilun, WuYongzhen translation. Beijing: Higher Education Press, 1965.

${ }^{19}$ P. Xie , H. J. Wen, and G. J. Wang, "An analytical solution of stress distribution around underground gas storage cavern in bedded salt rock". Journal of Renewable and Sustainable Energy, 10(3), 034101(2018).

${ }^{20}$ P. Xie, H. J. Wen, G. J. Wang, and J. Hu, "Theoretical analytical solution of deformation and stress distribution of underground gas storage cavern in bedded salt rock". Archives of Civil Engineering, LXIV(4), 37-53(2018). 
Figures

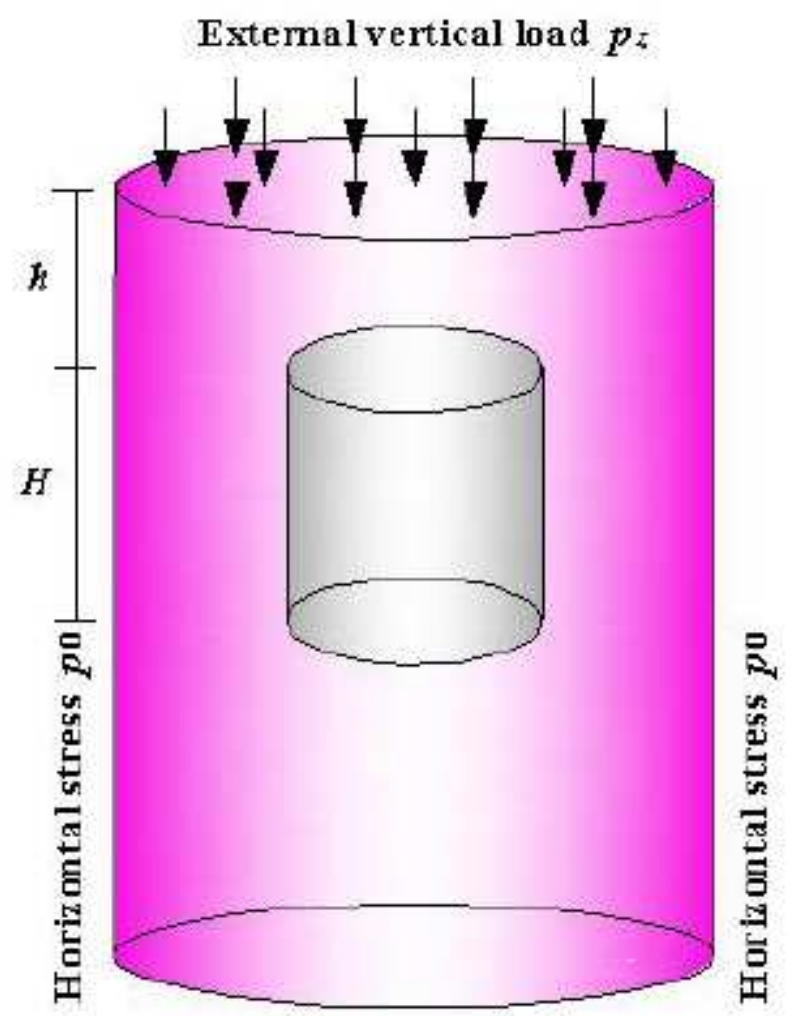

Figure 1

Sketch of limestone strata in a mantled Karst region, containing shallow buried cylinder Karst cave 


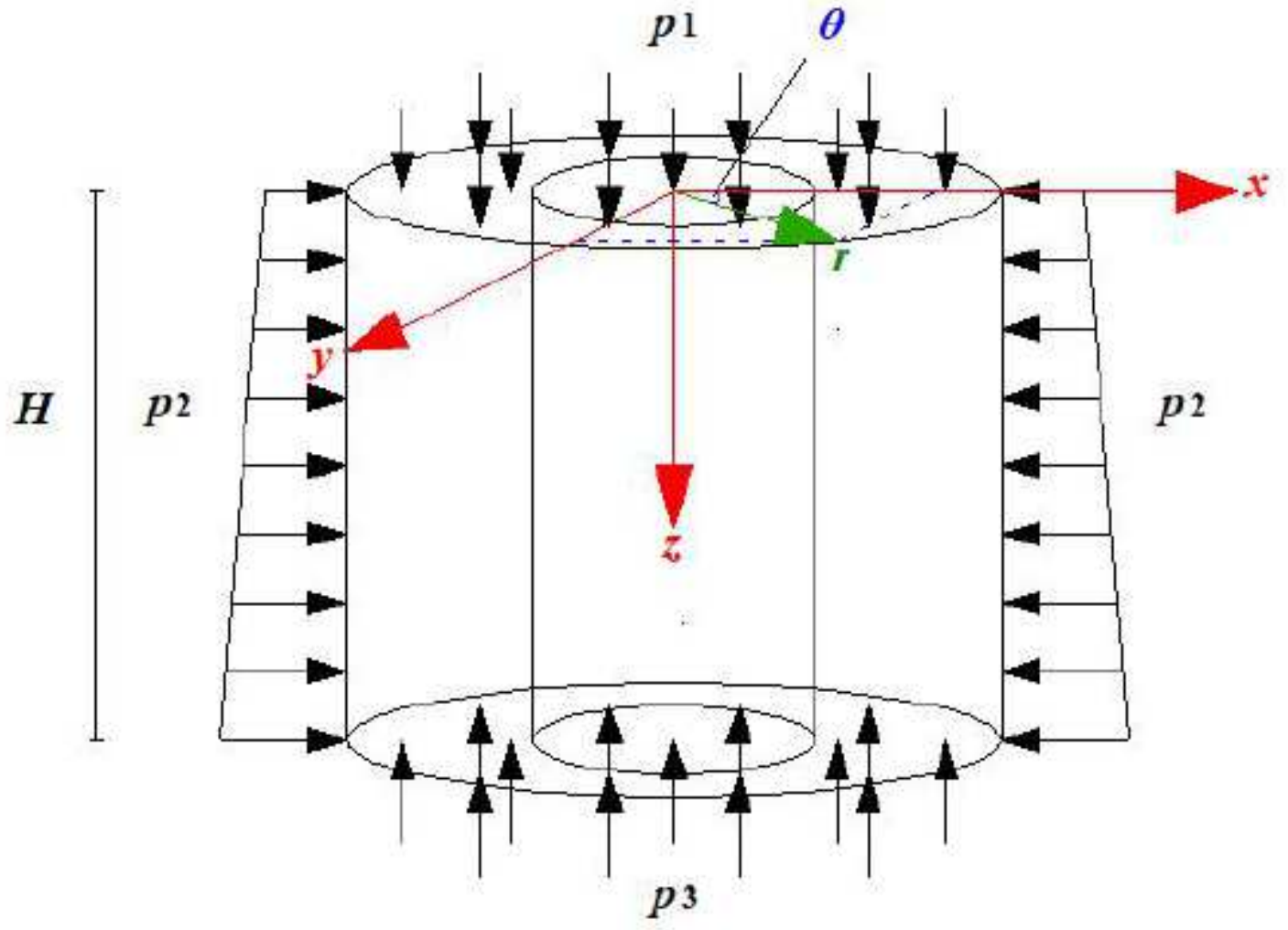

Figure 2

Mechanical model

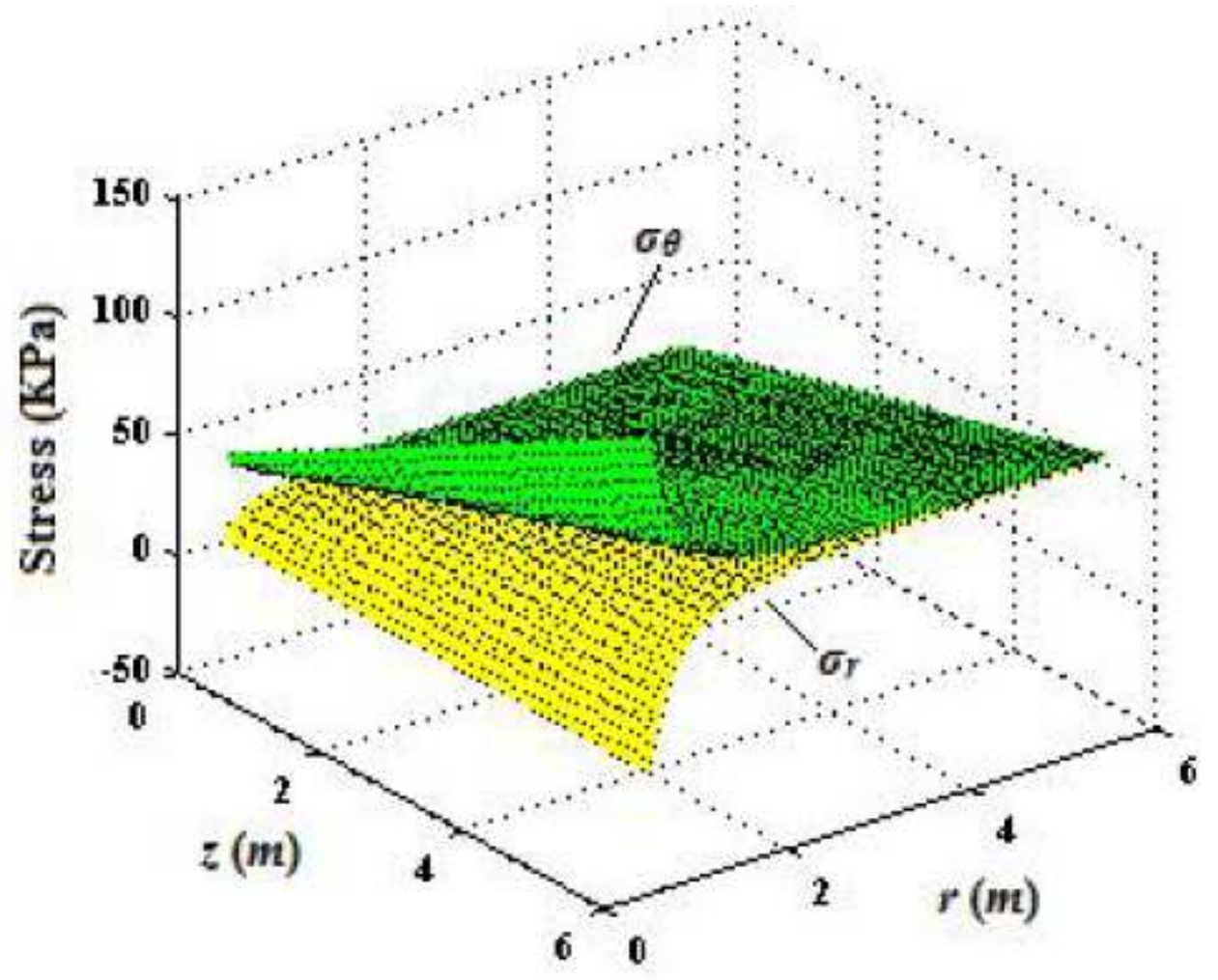

Figure 3 
The distribution of radial stress and circumferential stress

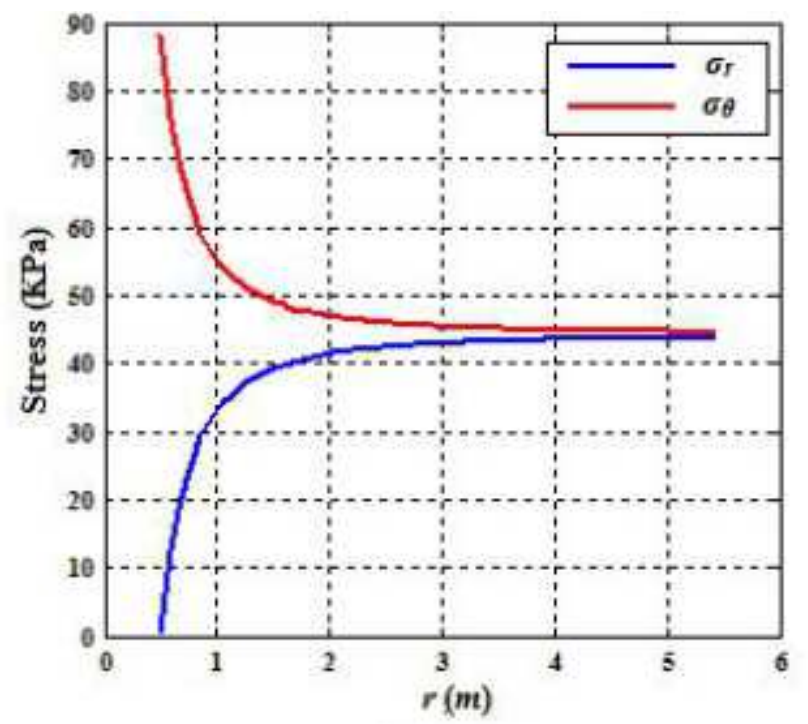

(a)

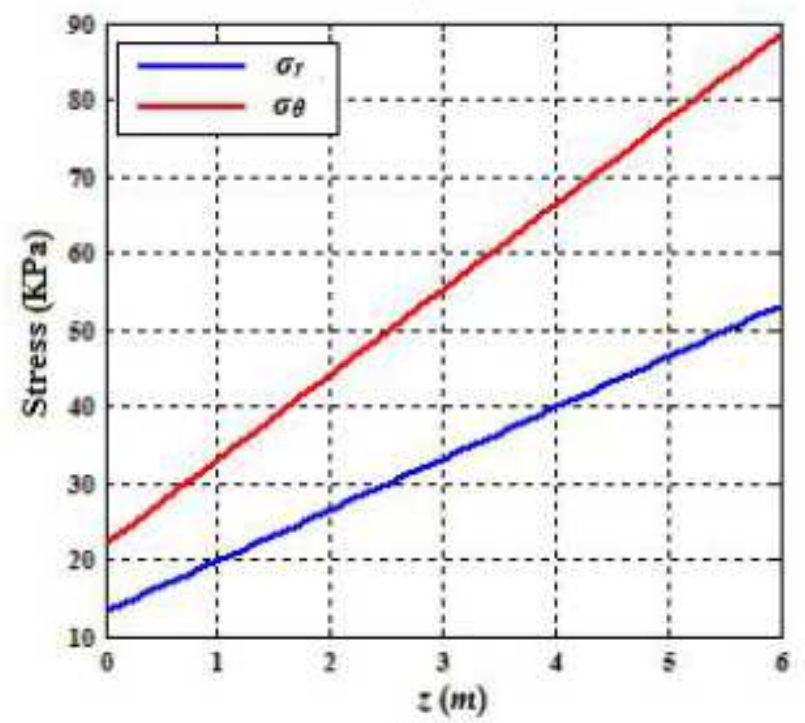

(b)

Figure 4

The distribution of radial stress and circumferential stress effected by single influencing factor (a) depth is constant $(z=3 m)$, radius varies from $0.5 \mathrm{~m}$ to $5.5 \mathrm{~m}$ (b) radius is constant $(r=1 \mathrm{~m})$, the depth varies from $0 \mathrm{~m}$ to $6 \mathrm{~m}$ 


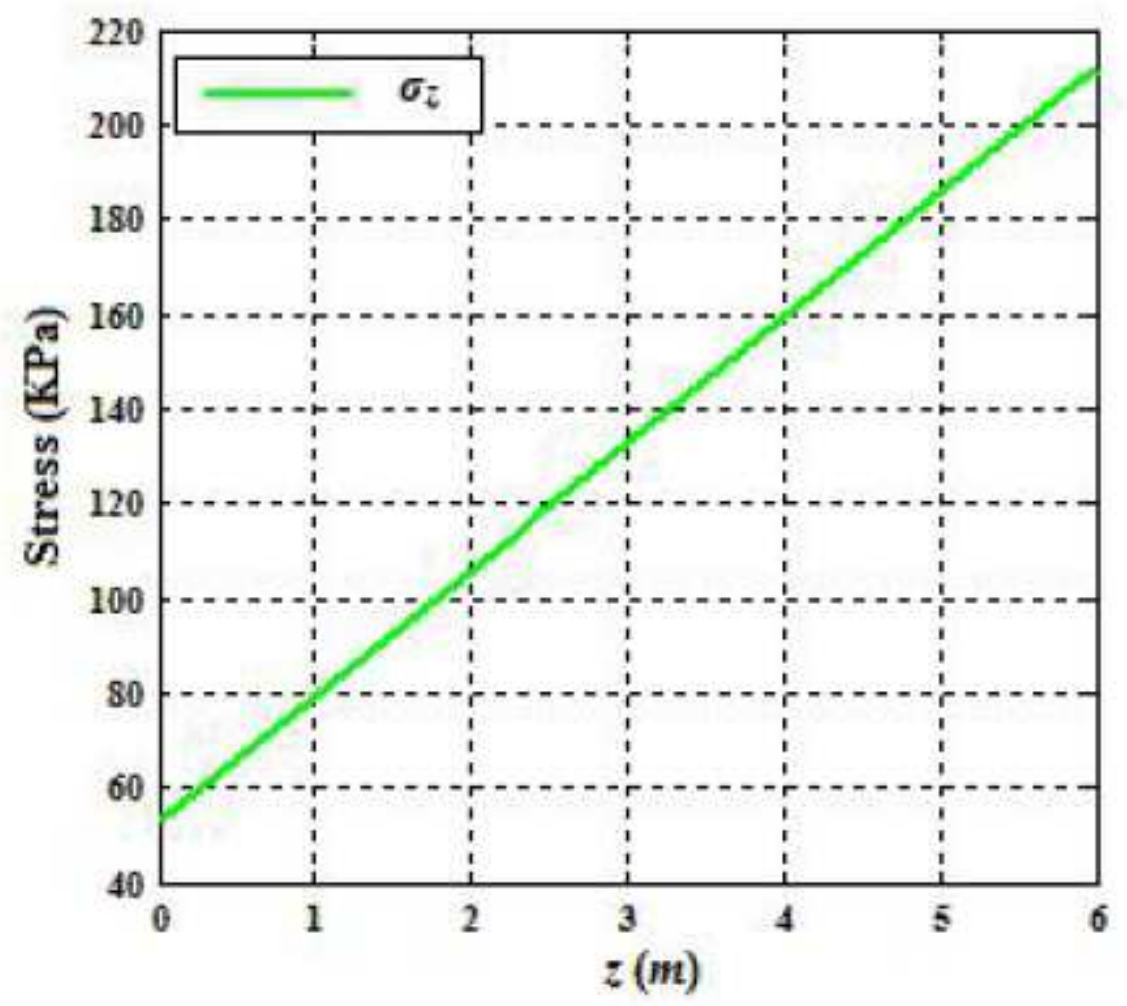

Figure 5

The distribution of vertical stress

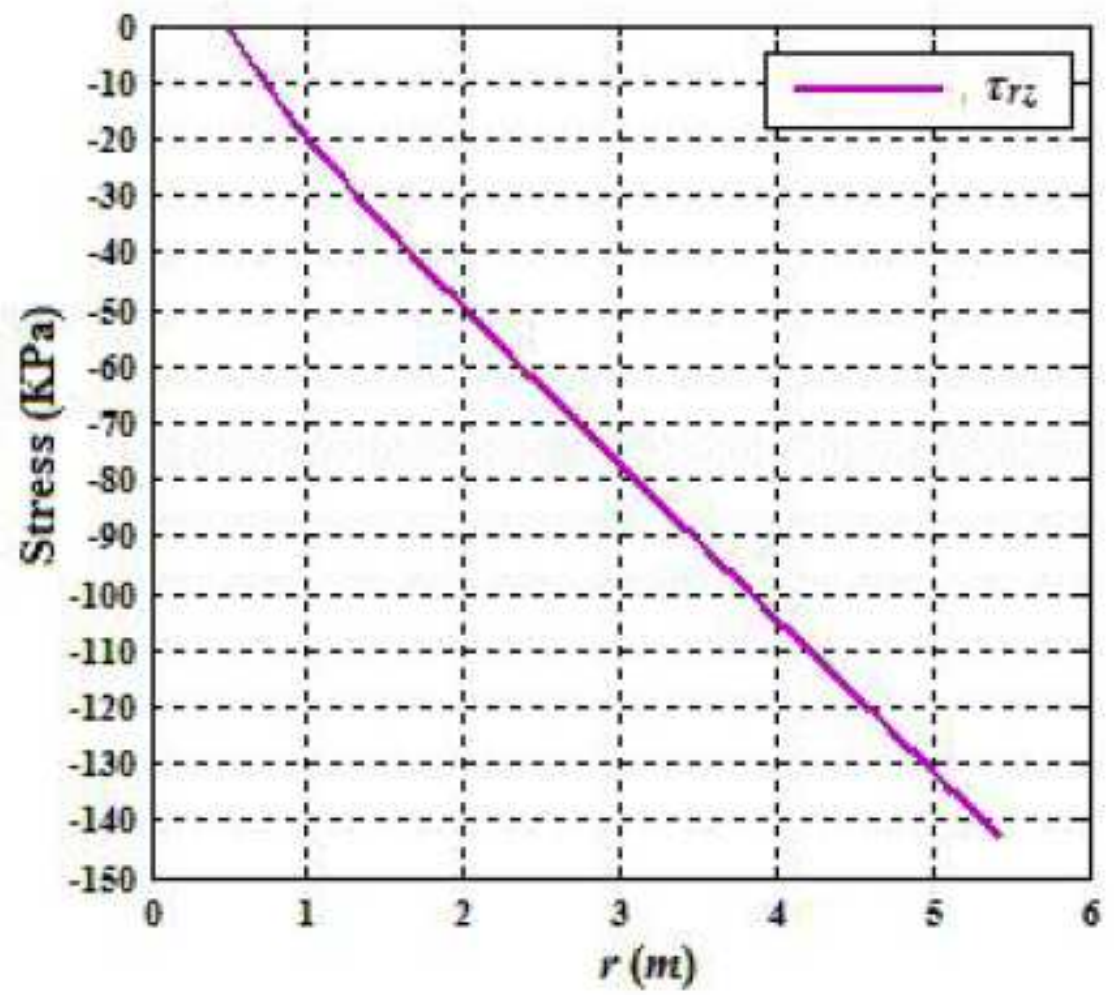

Figure 6 

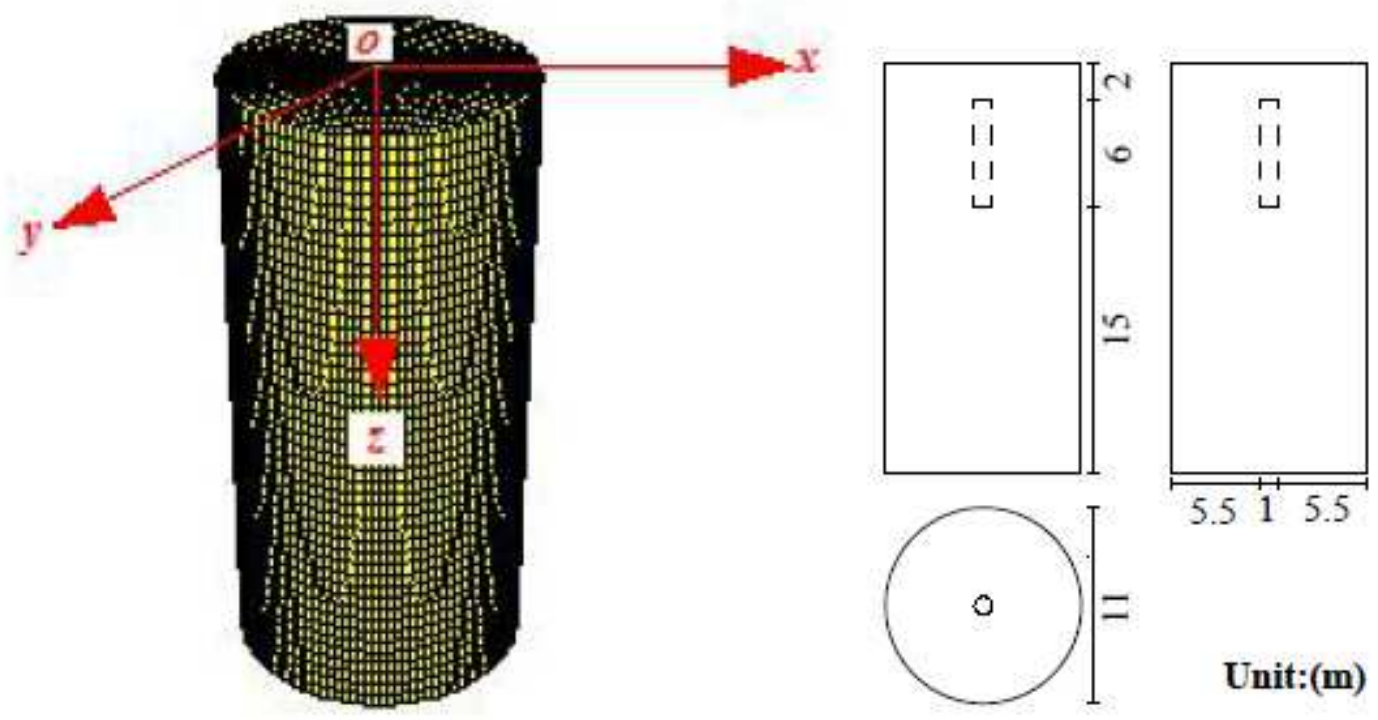

Figure 7

Sketch of model for numerical simulation

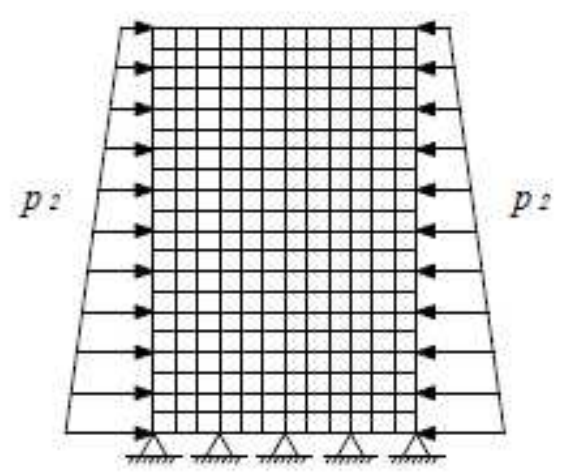

(a) vertical cross-section

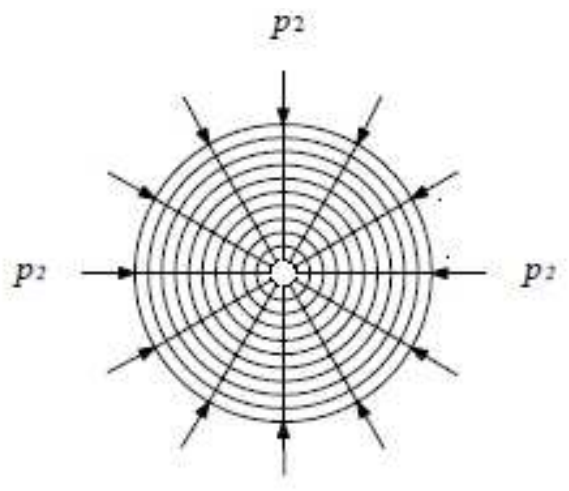

$p_{2}$

(b) horizontal cross-section

Figure 8

Sketch of constrained condition and boundary condition for numerical simulation model 


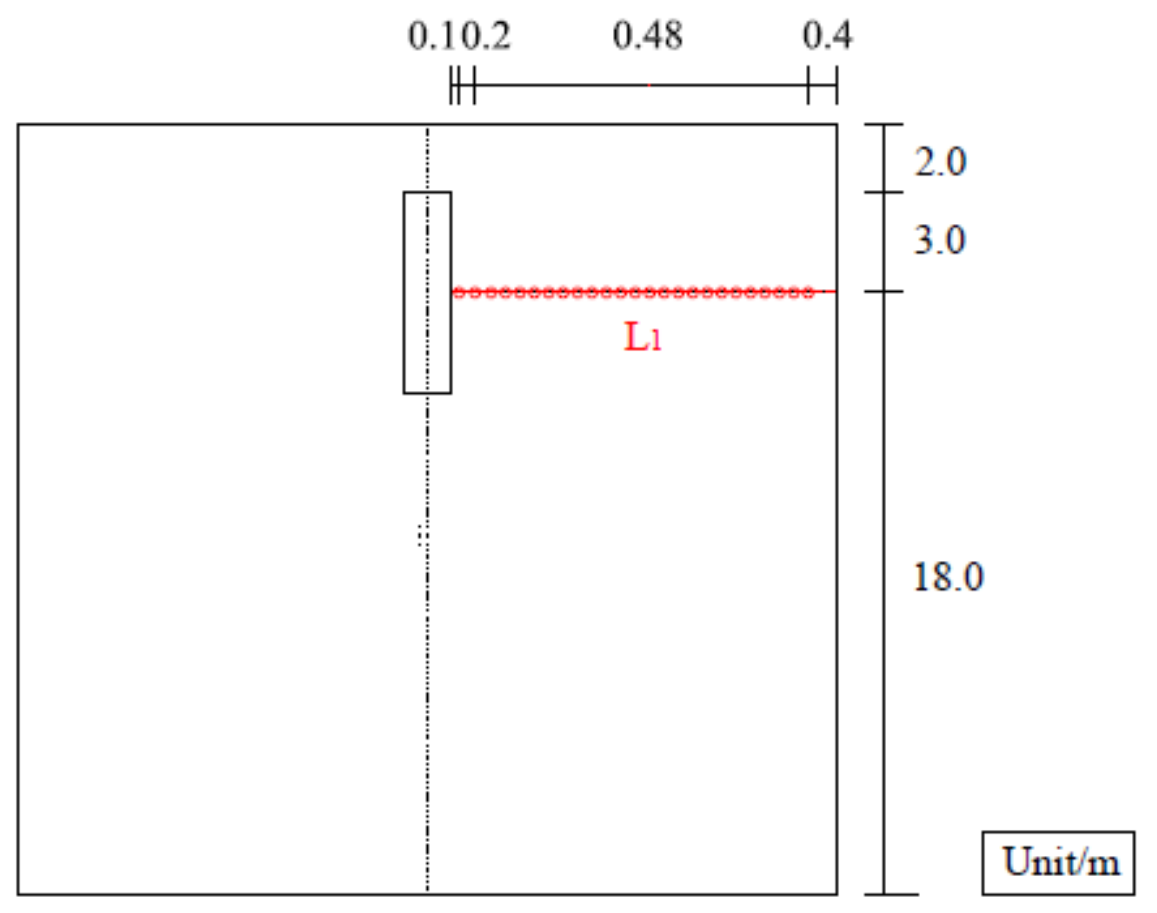

Figure 9

The layout of monitored area

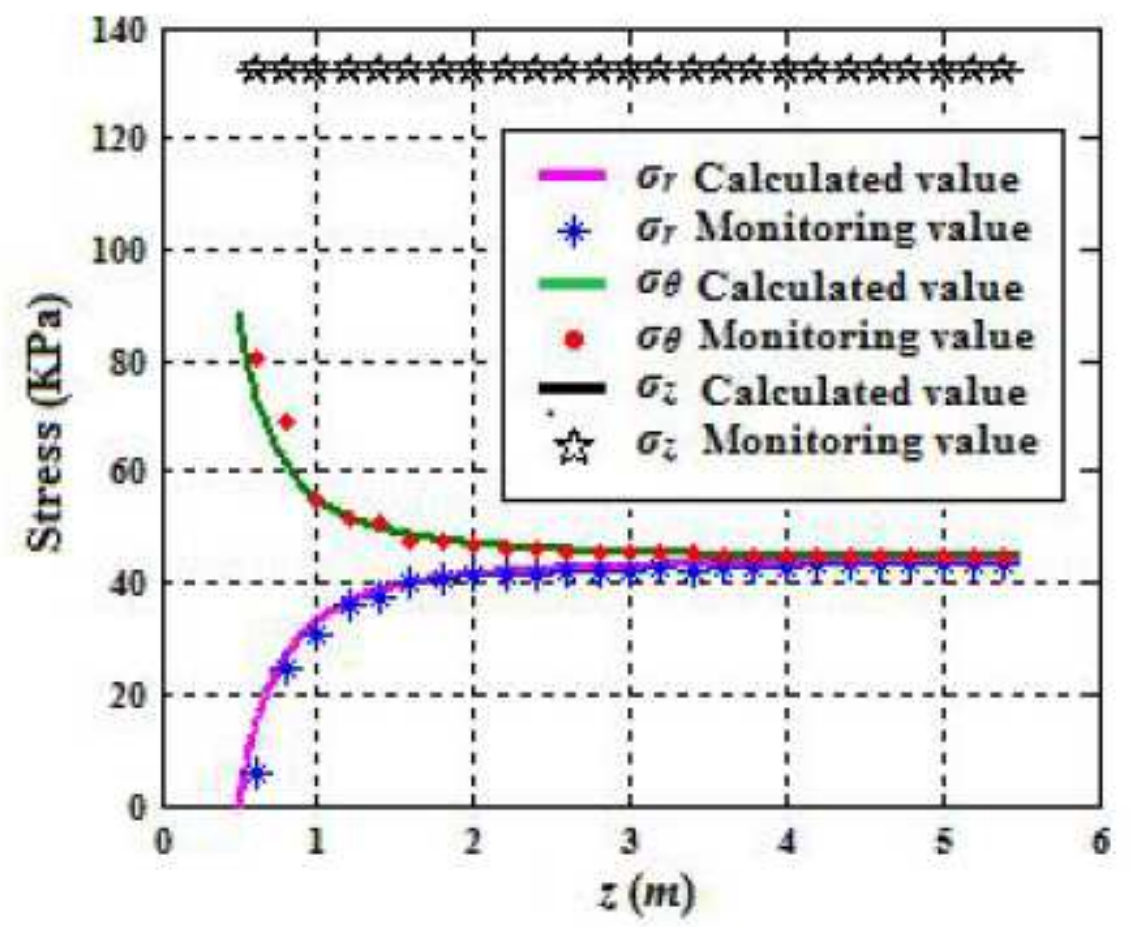

Figure 10

Comparisons of stress component between analytical solution and numerical simulation. 